\title{
Highlights of the University of Toronto Urology Update 2014
}

Cite as: Can Urol Assoc J 2015;9(1-2Suppl1):S3-9. hitrp://dx.doi.org/10.5489/cuaj.2670

Published online February 9, 2015.

\section{Abstract}

At the University of Toronto Urology Update 2014, a faculty of Canadian and American experts presented a series of lectures covering a range of topics in the field of urology. Areas of focus included prostate cancer $(\mathrm{PCa})$, functional urology, erectile dysfunction (ED), and surgical topics (e.g., percutaneous nephrolithotomy [PCNL]).

\section{Prostate cancer screening in 2014: The debate rages on}

\section{Highlights of presentations by Drs. Neil Fleshner, Girish Kulkarni, Anthony Miller and H. Ballentine Carter}

The utility of the serum prostate-specific antigen (PSA) test for the early detection of PCa has been the subject of vigorous debate among clinicians, researchers and policy-makers. As discussed at Urology Update 2014, authors of current and recent guidelines still do not agree on whether or not screening should be offered on a population basis.

\section{Evidence}

Many initiatives have been undertaken to apply evidence-based medicine to the question of whether or not PSA testing is beneficial in terms of hard endpoints (e.g., early identification of PCa, overall mortality), including six randomized, controlled trials (RCTs).$^{1-8}$ Of these six trials, the three that are considered to be Level 1 evidence are the Prostate Lung Colorectal Ovarian (PLCO) Cancer Screening Trial, 1,7 the European Randomized Study of Screening for Prostate Cancer (ERSPC) trial ${ }^{2,8}$ and the Göteborg study. ${ }^{3}$

The PLCO Cancer Screening Trial randomized 76,693 men to screening versus usual care. ${ }^{1}$ The two arms were well balanced at baseline for age and other important characteristics (e.g., family history of PCa, PSA testing and digital rectal exams [DREs] prior to study entry). In the screening arm, patients underwent six annual PSA tests and four DREs. In the usualcare arm, there were no recommendations for screening; but notably, there was substantial "contamination," with $40 \%$ having a PSA test within the first year, and $52 \%$ having a PSA test within the first six years. In the initial study report, with seven years of follow-up, there were significantly more PCa cases detected, with a rate ratio of $1.22(95 \%$ confidence interval [CI] 1.16-1.29). There was, however, no significant difference between the two arms in overall or PCa-specific mortality, even out to 13 years of follow-up, and substantially more men died of other causes than from PCa. ${ }^{7}$ Additionally, among PCa survivors, there was substantially decreased sexual and urinary function compared to non-cancer controls.

These observations provide the key evidence-based argument against routine PCa screening, as increased detection did not lead to a tangible benefit, and potential risks were associated with the overdiagnosis and overtreatment of potentially indolent cancers. As is evident from the substantial contamination rate, however, this may not be the best study on which to base recommendations.

The ERSPC trial included 162,243 men from seven countries. ${ }^{2}$ In the screening group, PSA screening was offered an average of once every four years (intervals varied across the participating countries). Patients in the control group did not receive routine screening. However, there was considerable contamination in this control group as well, with $23 \%$ to $40 \%$ of patients in the control arm having had their PSA tested.

For the primary outcome of PCa mortality over nine years, there was a significant difference in favour of the screening group, with a relative risk (RR) of $0.79(95 \% \mathrm{Cl} 0.69-0.91$, $p=0.0007){ }^{2}$

The Göteborg study included approximately 20,000 Swedish men aged 50 to 64 , followed for a median of 14 years. ${ }^{3}$ These men were randomized either to PSA testing every two years or no screening, and followed for 14 years. The contamination rate was low; only $3 \%$ of the control group received PSA screening. Screening did identify significantly more cases of PCa in this study: $11.4 \%$ versus $7.2 \%$ among controls. For the primary endpoint of PCa-specific mortality, screening reduced the risk by $44 \%$ (RR $0.56,95 \% \mathrm{Cl} 0.39-0.82, p=0.002){ }^{3}$

\section{Guidelines and position statements}

The most recent official guidelines of the Canadian Urological Association (CUA) recommend that PCa screening be offered to healthy men aged 50, with at least a 10-year life expectancy, and to younger men (age 40) if there is a family history of PCa or if the individual is of African descent. ${ }^{9}$ More recently, the Canadian Task Force on Preventive Health Care (CTFPHC) - formerly the Canadian Task Force on the Periodic Health Examination (CTFPHE ) — has come to a contrasting conclusion, 


\section{Table 1. Statement on prostate cancer screening: Canadian}

Urological Association, October 2014

1. Avoid PSA testing in men with little to gain. Men who decide to have a PSA and have a low value ( $<1.0$ at baseline) should be tested infrequently, about every 5 years. Men with less than a 15-year life expectancy (typically over age 70) should not be screened unless they previously had a high PSA. Men whose PSA is above the median for their age but below the biopsy threshold should be counselled for more regular screening and risk assessment.

2. DRE has value for the detection of many anal and rectal problems, as well as prostatic abnormalities in addition to PCa. DRE should continue to be performed as a routine part of the periodic health exam.

3. Do not treat men with low-risk PCa, or older men with intermediate-risk $\mathrm{PCa}$, who are not likely to benefit from treatment.

PSA: prostate-specific antigen; PCa: prostate cancer; DRE: digital rectal examination.

recommending that PSA screenings not be routinely offered to any men, regardless of age. ${ }^{10}$ This recommendation was largely based on the lack of benefit on overall mortality in clinical trials; however, the trials cited by the authors were not powered to detect such a benefit. These recommendations also overlook the fact that PCa mortality has declined $45 \%$ in Canada since 1995, a period roughly paralleling the rise in PSA screening rates.

Another contention is that the risks associated with further investigation (e.g., bleeding, infection associated with biopsy) and treatment (e.g., urinary and sexual side effects associated with surgery) outweigh the benefits of detection. This contention ignores the widespread adoption of active surveillance among Canadian clinicians.

In response to the Canadian task force recommendations, the CUA has issued a statement that revises the 2011 guidelines (Table 1). ${ }^{11}$

In his keynote Vincent Colapinto Memorial Lecture, Dr. Carter noted that, over time, with the advent of widespread screening, there are more and more low-risk cancers being identified and fewer high-risk cancers. ${ }^{12}$ This has led to the current state of management, where most treatment is directed at patients who have a non-lethal phenotype that is easily detected with screening, and resulting in widespread overtreatment. However, there is also a relative inability to detect high-risk cancers, which leads to undertreatment of these lethal tumours. What is now needed are efforts to define, identify and treat the lethal phenotype.

\section{Diagnosis and staging of prostate cancer}

\section{Highlights of presentations by Drs. Robert Nam, Laurent Milot and Samir Taneja}

The continuing debate about the desirability of populationbased screening with the PSA test and the potential harms of prostate biopsy highlight the imperfect nature of these screening and diagnostic tools for PCa. At Urology Update 2014, faculty members presented a series of lectures discussing the potential of magnetic resonance imaging (MRI) as a tool for diagnosis to help improve accuracy of prostate biopsy.

\section{MRI for screening and diagnosis of prostate cancer}

The goals of using MRI for the diagnosis of PCa are to: reduce the morbidity associated with unnecessary biopsies, reduce the detection rate of indolent disease (to avoid morbidity of unnecessary treatment), and improve the detection of clinically significant disease. The negative predictive value for prostate MRI is approximately 95\%; as such, judicious use of MRI could eliminate unnecessary biopsies in many men after potential risk is identified through the front-line screening modalities (i.e., PSA test and DRE). The specificity of MRI for identification of clinically significant cancers is also exceptional, at approximately $90 \%$.

The potential utility of MRI for PCa screening has been investigated in a pilot study at Toronto's Sunnybrook Hospital. The subjects were 46 men who received a PSA test, MRI and biopsy. Twenty-nine of the patients had a PSA $<4 \mathrm{ng} / \mathrm{mL}$, and the other 17 had a PSA $\geq 4 \mathrm{ng} / \mathrm{mL}^{13}$

Among those with a "normal PSA," abnormal prostates (MRI score of 4 or 5 on a 5 -point scale) were detected in $28 \%$ of patients. Among those with PSA of $4 \mathrm{ng} / \mathrm{mL}$ or higher, MRI detected abnormal prostates in $48 \%$ of patients. The detection of clinically significant cancers was enhanced by using MRI in the normal PSA group. The negative predictive value in this study was $86 \%$, compared to $72 \%$ with PSA alone. Although these data are from a small pilot study, the conclusion from the investigators was that MRI-assisted screening is feasible and should be considered.

\section{MRI-assisted prostate biopsy}

MRI is a powerful tool in guiding biopsy to properly sample lesions for staging and risk stratification.

The biopsy can be performed during the MRI which, with proper training, can be highly effective for enhancing the accuracy of the biopsy. ${ }^{14-16}$ This is a long, costly and physically difficult procedure and is, therefore, only useful as a research tool.

A more practical approach is to use the MRI findings to inform an ultrasound (US)-guided biopsy, which can be accomplished through the use of image fusion methods. This can be done by the radiologist through careful review of the MRI and application of this knowledge during the US-guided biopsy, or through the use of a device that fuses the MRI data with the US imaging in real time.

The seminal evidence supporting the use of MRI to inform US-guided biopsy was published in 2011 by Haffner et al. ${ }^{17}$ In their study of 555 patients with suspicion of PCa, they concluded that a strategy of targeted biopsies alone at pre-biopsy MRI- 
suspicious areas may be preferred to extended systematic biopsies for detection of clinically significant PCa. ${ }^{17}$

Investigators at Sunnybrook Hospital have recently published a study in which such a device was compared with standard US-guided biopsy in 72 men under active surveillance. ${ }^{18}$ The study showed that the image fusion technique (UroNavBx) was significantly better at detecting clinically significant PCa compared to standard US-guided biopsy (more than six-fold more likely to yield a core positive for clinically significant cancer), with substantially fewer cores required (in this study, 2-3 cores taken with the image fusion and 12 with standard US-guided biopsy). ${ }^{17}$ Detection rates for each method with respect to Gleason $\geq 7$ cancer and $\geq$ high-volume Gleason 6 cancer are shown in Table 2.

\section{Miscellaneous prostate cancer updates 2014}

\section{Highlights of presentations by Drs. Neil Fleshner and Alex Zlotta}

\section{Metformin and prostate cancer}

Evidence shows that there is a link between the metabolic syndrome and PCa risk, with patients who have more individual components of the metabolic syndrome having a greater risk of $\mathrm{PCa} .{ }^{19}$ Although the underlying mechanisms of the association are not clear, one of the hypotheses is that diet-induced hyperinsulinemia drives accelerated PCa growth. ${ }^{20}$ This potential link has led to studies examining the impact of antihyperglycemic interventions typically used for type 2 diabetes on PCa risk. A recently published single-arm pilot study investigated the utility of neoadjuvant metformin prior to radical prostatectomy for PCa. ${ }^{21}$ In per-patient and per-tumour analyses, the use of neoadjuvant metformin reduced the Ki67 index by $29.5 \%$ and $28.6 \%$, respectively (both $p<0.01$ ). The positive effects in this small trial are supported by observational database analysis, in which it has been shown that metformin use among patients with diabetes is associated with lower rates of PCa compared to patients with diabetes who did not receive this drug. ${ }^{22}$ The

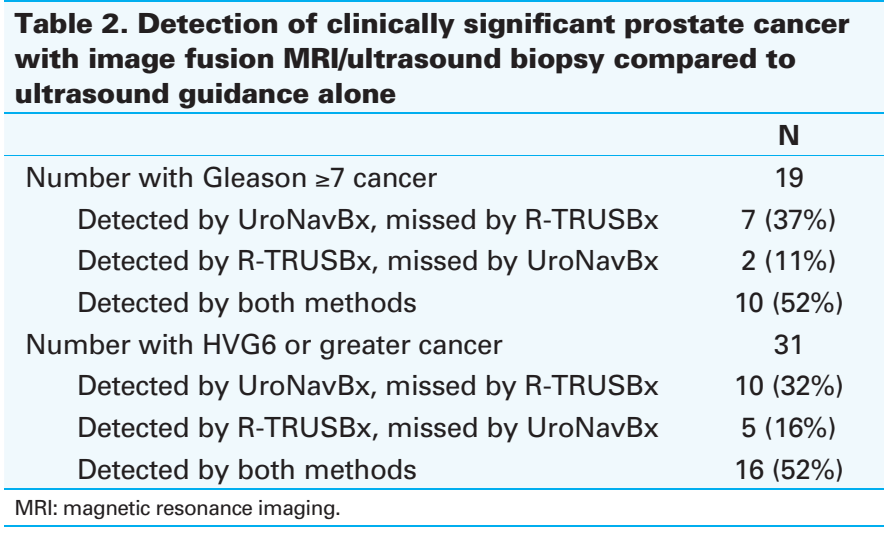

association between metformin and PCa is now being studied in the ongoing, prospective Metformin Active Surveillance Trial (MAST) study.

\section{Baldness and prostate cancer}

Male pattern baldness has also been identified as a strong and independent risk factor both for PCa overall and for high-grade disease. ${ }^{23}$ This may be a useful additional "screening tool" that can be easily applied in the clinic.

\section{Chronic inflammation and prostate cancer}

Prostate inflammation has been identified as a common finding in PCa. ${ }^{24}$ The association between inflammation and PCa has been investigated in a cross-sectional study of unscreened Caucasian ( $n=220$ from Moscow, Russia) and Asian ( $n=100$ from Tokyo, Japan) men. ${ }^{25}$ The investigators of this study reported that Asians with chronic inflammation were 3.5 times more likely to have PCa than those without chronic inflammation. This association was not present for Caucasian men.

\section{Post-prostatectomy erectile dysfunction}

\section{Highlights of a presentation by Dr. Arthur L. Burnett}

One of the most common treatment-related morbidities following radical prostatectomy is ED, occurring in 15 to $40 \%$ of the post-prostatectomy population. ${ }^{26}$ The desired strategy for individuals with post-surgical ED is to intervene early in an effort to achieve erection rehabilitation. This concept involves early post-intervention sexual stimulation and induced blood flow in the penis to facilitate the return of natural erectile function and resumption of medically assisted sexual activity.

Interventions that have demonstrated utility for penile rehabilitation in this setting include intracavernosal injection of alprostidil, ${ }^{27}$ oral phosphodiesterase type 5 (PDE-5) inhibitor treatment ${ }^{28-31}$ (i.e., sildenafil, tadalafil, vardenafil), vacuum erection devices, ${ }^{32,33}$ transurethral pharmacotherapy, ${ }^{34}$ and sexual counselling. ${ }^{35}$

With respect to PDE-5 inhibitors, research suggests that an on-demand approach is as effective, if not moreso, than a daily regimen. The Recovery of Erections: INtervention with Vardenafil Early Nightly Therapy (REINVENT) trial compared vardenafil $10 \mathrm{mg}$ nightly to vardenafil $20 \mathrm{mg}$ on demand or placebo in men within 14 days following bilateral nerve-sparing radical prostatectomy. ${ }^{29}$ During the trial's nine-month active treatment period, on-demand vardenafil was associated with the best erectile response. 


\section{Functional urology 2014}

\section{Highlights of presentations by Drs. Ann Gormley, Sender Herschorn and J. Quentin Clemens}

\section{Overview of guidelines on overactive bladder (OAB)}

Part of the session on functional urology was dedicated to an overview of recent updates to the American Urological Association/Society of Urodynamics, Female Pelvic Medicine and Urogenital Reconstruction (AUA/SUFU) guidelines for $\mathrm{OAB},{ }^{36}$ which were last updated in 2012. For the 2014 update, the authors reviewed 72 new articles on the treatment of OAB. While there were no changes in the recommendations for diagnosis, there were several substantive changes to the treatment recommendations.

Many of these changes are in response to the accumulation of evidence in support of the beta-3-adrenergic agonist class (i.e., mirabegron) as an oral option (in addition to the largely unchanged recommendations for oral antimuscarinic agents).

Another important addition to the guidelines is the endorsement of onabotulinumtoxinA as a third-line option for patients who are able and willing to return for post-void residuals and to perform self-catheterization. This was also in recognition of the high-quality evidence demonstrating efficacy of this intervention that has emerged since the last guideline update.

Peripheral tibial nerve stimulation (PTNS) has also been upgraded from an "option" in the prior guidelines to a "recommendation" in the 2014 guidelines due to a number of positive studies in recent years.

Another important change to the guidelines is the definition of what constitutes a refractory patient. The new definition is a "patient who has failed a trial of symptom-appropriate behaviour therapy of sufficient length-8 to 12 weeks-and who has failed a trial of at least one anti-muscarinic administered for 4-8 weeks."

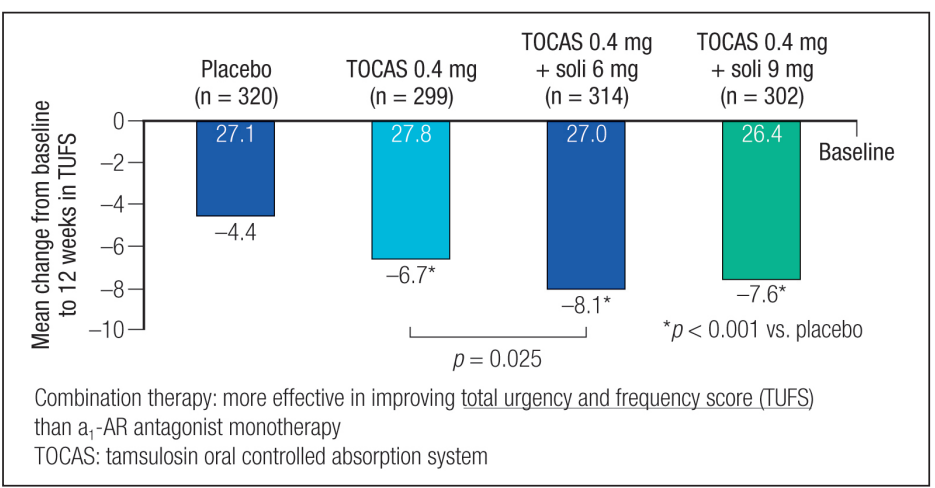

Fig. 1. Combination alpha-blocker and antimuscarinic in overactive bladder: The NEPTUNE Trial.

\section{New drugs for $O A B$}

As part of the Urology Update program, there was also a review of recently published clinical trial evidence for new therapies for the treatment of $\mathrm{OAB}$ or nocturia. While no new antimuscarinics have been introduced, there will likely soon be a fixeddose combination therapy combining an alpha-blocker with an antimuscarinic for the treatment of persistent $O A B$ symptoms in males. This approach has been shown to be effective in the Study of Solifenacin Succinate and Tamsulosin Hydrochloride OCAS in Males With Lower Urinary Tract Symptoms (NEPTUNE) trial, which evaluated two fixed-dose combinations of tamsulosin and solifenacin and found this combination to be superior to alpha-blocker monotherapy for the improvement of total urgency and frequency score (Fig. 1). ${ }^{37}$

The recent clinical trial experience with the beta-3-adrenergic agonist mirabegron was also summarized, showing that this agent is as efficacious as antimuscarinics in reducing frequency, incontinence and urge urinary incontinence (UUI). ${ }^{3}$ From a tolerability standpoint, the major difference with mirabegron relative to the antimuscarinics is a significantly lower incidence of dry mouth. ${ }^{38}$

Importantly, the combination of an antimuscarinic (solifenacin) and mirabegron for patients with $\mathrm{OAB}$ has demonstrated greater efficacy than antimuscarinic monotherapy (in the Phase 2 Symphony study). ${ }^{39}$ This has led to the initiation of a very large Phase 3 trial, the largest $O A B$ study ever designed, with an enrolment goal of 3500 patients.

Data in support of the use of onabotulinumtoxinA were also presented. A 24-week, Phase 3 study in 557 patients with OAB and urinary incontinence showed that the intervention was associated with significant reductions in urinary incontinence (Fig. 2), micturition, urgency and nocturia episodes..$^{40}$ Other researchers have shown that efficacy outcomes among responders are sustained after repeated injections ${ }^{41}$ and that persistence

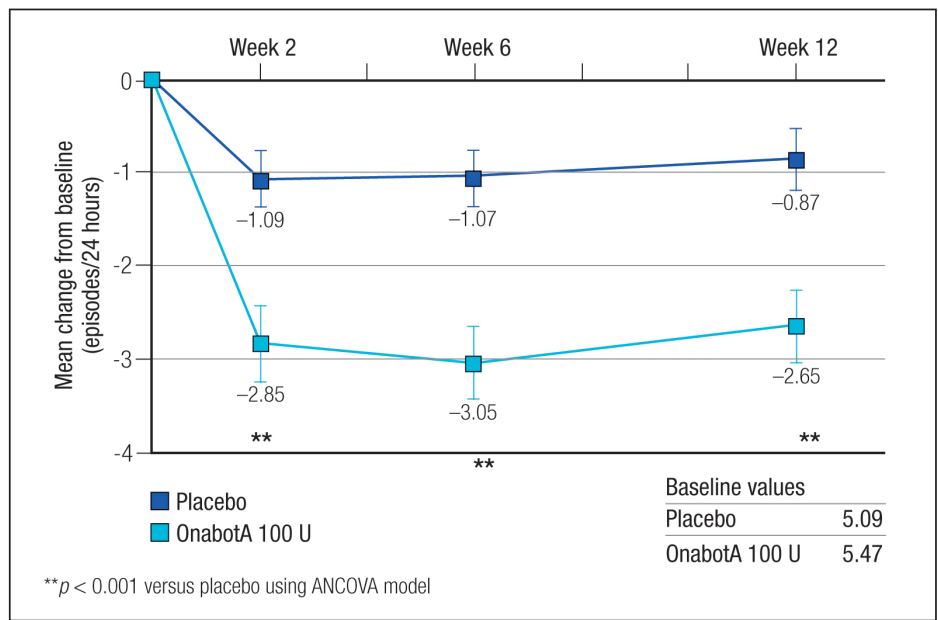

Fig. 2. OnabotulinumtoxinA versus placebo for overactive bladder: Reduction in urinary incontinence episodes. 
with this therapy is approximately $40 \%$ at five years, ${ }^{42}$ whichwhile not optimal-is much better than observed persistence rates with antimuscarinic medications.

\section{New drugs for nocturia}

Low-dose desmopressin is known to be efficacious for the treatment of nocturia. This agent is available in oral tablets and in the newly released orally disintegrating tablets (ODT). ${ }^{43}$ Over the past two or three years, several studies have been published showing the efficacy of ODT in men and women with nocturia. ${ }^{44-46}$ Desmopressin can be used in combination with other pharmacotherapies (e.g., alpha-blockers) in patients who are being treated for lower urinary tract symptoms (LUTS) and have nocturnal polyuria in their symptoms. ${ }^{47,48}$

\section{Update on neuromodulation for $O A B$ and retention}

There are three neuromodulatory modalities that are indicated for the treatment of OAB: sacral neuromodulation, PTNS, and botulinum toxin injection. There have not been any published or presented head-to-head studies comparing these treatments. However, all three have demonstrated efficacy of a greater magnitude than that achieved with pharmacotherapy in idiopathic OAB. PTNS is perhaps the best accepted of the treatments from the patient perspective, with no complications. In the United States, it is also the least costly of the three treatments. ${ }^{49}$ The preferred regimen is 12 weekly sessions, followed by monthly treatments. This regimen has been shown to be effective out to three years. ${ }^{50}$ The frequency of in-clinic treatments is perhaps the most limiting aspect of this treatment, as it is inconvenient for some patients. There are no published Canadian PTNS studies to date.

\section{Laparoscopy and minimally invasive surgery 2014}

\section{Highlights of a debate by Drs. J. Stuart Wolf Jr. and Jason}

Standard care following percutaneous nephrolithotomy has been the placement of a large-calibre nephrostomy tube, with or without a ureteral extender. The advantages of using a nephrostomy tube include more assured drainage, control of drainage, and maintenance of percutaneous access for additional procedures, including second-look nephroscopy. This can lead to improved stone-free rates and decrease future stone events.

The use of a large-calibre tube (e.g., 20-24 Fr) is not, however, supported by the evidence. Analysis of the literature shows that a smaller-calibre tube $(8-18 \mathrm{Fr})$ has been associated with less pain and less urinary leakage compared to larger tubes..$^{51-56}$ Importantly, there is no further advantage in pain levels to opting for a tubeless approach (i.e., internal ureteral stent) compared to a small-calibre external tube. A 2012 meta-analysis of stud- ies comparing tubes of differing sizes and tubeless approaches concluded that the clinical efficacy and safety of tubeless and small-tube procedures are similar. ${ }^{57}$

It should be noted that the safety and efficacy of a tubeless approach has only been shown among selected patients. Randomized studies have excluded patients with evidence of hemorrhage or perforation, or who are at high risk for residual stone.

\section{Pediatric urology: Transition and long-term outcomes of the augmented patient}

\section{Highlights of a presentation by Dr. Mark Cain}

Bladder augmentation for children with spina bifida is instrumental in helping preserve renal function, maintain an intact urinary tract, achieve continence, and improve social wellbeing. However, there are also a number of issues that urologists need to be aware of among patients with augmented bladders. This is especially important, as most of these patients can now be expected to survive through adolescence and into adult life..$^{58}$ In the largest series published to date $(n=500$, Indianapolis, IN) following children post-bladder augmentation, $30 \%$ of these children experienced complications requiring surgery. ${ }^{59}$ While the majority of these involved removal of bladder or renal stones, a substantial proportion were to address more serious complications, such as bowel obstruction, bladder perforation, and transitional cell carcinoma (TCC) of the bladder. Metabolic complications (e.g., B12 deficiency) are also common. ${ }^{60}$

\section{Bowel obstruction}

Bowel obstruction is a post-augmentation complication for which risk is elevated for the rest of a patient's life. Among the 500 patients in the Indianapolis cohort, $3.2 \%$ (16 patients) experienced bowel obstruction. ${ }^{59}$ Most of these were subsequent to gastric augmentation, which is no longer a preferred surgical option. The mean time to this complication was 51 months post-augmentation.

\section{Bladder perforation}

One of the potentially lethal complications, there were $53 \mathrm{blad}$ der ruptures among 41 patients recorded in the 500-patient Indianapolis series. ${ }^{59}$ These perforations were almost universally symptomatic, with variable presenting complaints (e.g., abdominal pain, poor feeding, vomiting). Importantly, all patients had increased fluid on computed tomographic cystogram; this imaging modality is thought to be the best method of identifying these perforations. Bladder perforations appear to be an age- 
dependent phenomenon, with the peak incidence from 10 to 15 years of age and declining thereafter.$^{59}$ It is critical to see these at-risk patients on a regular basis to reinforce the importance of scheduled catheterizations. History of bladder-neck surgery is also a risk factor for perforation.

Management of bladder perforation in patients post-augmentation typically consists of laparotomy, externalization of the ventricular-peritoneal (VP) shunt, bladder closure, and drainage.

\section{Transitional cell carcinoma of the bladder}

Among patients post-bladder augmentation, the risk of TCC is approximately six to seven times that of the general population. ${ }^{61}$ Notably, patients with congenital bladder dysfunction due to neurologic abnormalities, exstrophy, and posterior urethral valves who are treated with intermittent catheterization, whether or not they undergo augmentation, have an increased risk of TCC compared to the general population (3- to 4-fold). ${ }^{61}$

The unfortunate reality of TCC in this population is that by the time these tumours are diagnosed, they are typically already at an advanced stage. In an earlier analysis of the Indianapolis cohort, of the 483 patients evaluable at that time (260 of whom had more than 10 years of follow-up), three patients had presented with TCC, each of which was metastatic at diagnosis. ${ }^{61}$ For those three patients, the ages at augmentation were 8, 20 and 24 years, and the ages at TCC diagnosis were 29, 37 and 44 years, respectively. ${ }^{62}$ This observation, supported by findings at other centres, ${ }^{63}$ is an important one, as these cancers will be seen by adult urologists, not the pediatric specialists who follow them at and around the time of their augmentations.

To date, no effective monitoring technique has been proposed that has been shown to lead to earlier identification of TCC in this population. Annual ultrasound and kidney, ureter and bladder (KUB) X-ray are reasonable recommendations; any finding of hematuria, recurrent urinary tract infection, pain or mass identified on ultrasound should undergo cystoscopy.

\section{Bladder stones}

Approximately $15 \%$ of patients in the Indianapolis cohort developed bladder stones during follow-up, with the mean time to the first stone being 5.6 years. ${ }^{59}$ In a retrospective review of 107 post-augmentation patients treated for bladder stones, median time to first stone surgery was 3.1 years post-augmentation. ${ }^{64}$ Overall, $47.7 \%$ of stones were fragmented, but the presence or absence of fragmentation made no difference in the risk of stone recurrence. ${ }^{63}$ The most important aspect of stone removal is postoperative irrigation to aggressively lavage the mucous out of the bladder.

\section{References}

1. Andriole GL, Crawford ED, Grubb RL 3rd, et al. Mortality results from a randomized prostate-cancer screening trial. N Engl J Med 2009;360:1310-9. http://dx.doi.org/10.1056/NEJMoa0810696

2. Schröder FH, Hugosson J, Roobol MJ, et al. Screening and prostate-cancer mortality in a randomized European study. N Engl J Med 2009;360:1320-8. http://dx.doi.org/10.1056/NEJMoa0810084

3. Hugosson J, Carlsson S, Aus $G$, et al. Mortality results from the Göteborg randomised population-based prostatecancer screening trial. Lancet Oncol 2010;11:725-32. http://dx.doi.org/10.1016/S1470-2045(10)70146-7

4. Sandblom G, Varenhorst E, Rosell J, et al. Randomised prostate cancer screening trial: 20-year follow-up. BMJ 2011;342:d1539.

5. Kjellman $A$, Akre 0 , Norming $U$, et al. 15-year followup of a population based prostate cancer screening study. J Urol 2009;181:1615-21. http://dx.doi.org/10.1016/i.juro.2008.11.115

6. Labrie F, Candas B, Cusan L, et al. Screening decreases prostate cancer mortality: 11-year follow-up of the 1988 Quebec prospective randomized controlled trial. Prostate 2004;59:311-8. http://dx.doi.org/10.1002/ pros.20017

7. Andriole GL, Crawford ED, Grubb RL 3rd, et al. Prostate cancer screening in the randomized Prostate, Lung, Colorectal, and Ovarian Cancer Screening Trial: Mortality results after 13 years of follow-up. J Natl Cancer Inst 2012;104:125-32. http://dx.doi.org/10.1093/inci/dir500

8. Schröder FH, Hugosson J, Roobol MJ, et al. Screening and prostate cancer mortality: Results of the European Randomised Study of Screening for Prostate Cancer (ERSPC) at 13 years of follow-up. Lancet 2014;384:202735. http://dx.doi.org/10.1016/S0140-6736(14)60525-0

9. Izawa Jl, Klotz L, Siemens DR, et al. Prostate cancer screening: Canadian guidelines 2011. Can Urol Assoc J 2011;5:235-40. http://dx.doi.org/10.5489/cuaj.11134

10. Bell N, Gorber SC, Shane A, et al. Recommendations on screening for prostate cancer with the prostate-specific antigen test. CMAJ 2014;186:1225-34. http://dx.doi.org/10.1503/cmaj.140703

11. Klotz L, Breau R, Chin J, et al. Press release from the Canadian Urological Association. October 27, 2014.

12. Cooperberg MR, Moul JW, Carroll PR. The changing face of prostate cancer. J Clin Oncol 2005;23:8146-51. http://dx.doi.org/10.1200/JC0.2005.02.9751

13. Nam R, et al. Unpublished data, presented at the 2014 University of Toronto Urology Update. Friday, October $31,2014$.

14. Hambrock T, Somford DM, Hoeks C, et al. Magnetic resonance imaging guided prostate biopsy in men with repeat negative biopsies and increased prostate specific antigen. J Urol 2010;183:520-7. http://dx.doi. org/10.1016/i.juro.2009.10.022

15. Beyersdorff D, Winkel A, Hamm B, et al. MR imaging-guided prostate biopsy with a closed MR unit at $1.5 \mathrm{~T}$ : Initial results. Radiology 2005;234:576-81.

16. Yacoub JH, Verma S, Moulton JS, et al. Imaging-guided prostate biopsy: Conventional and emerging techniques. Radiographics 2012;32:819-37. http://dx.doi.org/10.1148/rg.323115053

17. Haffner J, Lemaitre L, Puech P, et al. Role of magnetic resonance imaging before initial biopsy: Comparison of magnetic resonance imaging-targeted and systematic biopsy for significant prostate cancer detection. BJU Int 2011;108:E171-8.

18. Da Rosa MR, Milot L, Sugar L, et al. A prospective comparison of MRI-US fused targeted biopsy versus systematic ultrasound-guided biopsy for detecting clinically significant prostate cancer in patients on active surveillance. J Magn Reson Imaging 2015;41:220-5. http://dx.doi.org/10.1002/imri.24710. Epub 2014 Jul 21.

19. Bhindi B, Locke J, Alibhai SM, et al. Dissecting the association between metabolic syndrome and prostate cancer risk: Analysis of a large clinical cohort. Eur Urol 2015;67:64-70. http://dx.doi.org/10.1016/i.eururo.2014.01.040. Epub 2014 Feb 14

20. Venkateswaran V, Haddad AQ, Fleshner NE, et al. Association of diet-induced hyperinsulinemia with accelerated growth of prostate cancer (LNCaP) xenografts. J Natl Cancer Inst 2007;99:1793-800. http://dx.doi. org/10.1093/inci/dim231

21. Joshua AM, Zannella VE, Downes MR, et al. A pilot 'window of opportunity' neoadjuvant study of mefformin in localised prostate cancer. Prostate Cancer Prostatic Dis 2014;17:252-8. http://dx.doi.org/10.1038/ pcan. 2014.20

22. Margel D, Urbach DR, Lipscombe LL, et al. Mefformin use and all-cause and prostate cancer-specific mortality among men with diabetes. J Clin Oncol 2013;31:3069-75. http://dx.doi.org/10.1200/JC0.2012.46.7043

23. Zhou CK, Pfeiffer RM, Cleary SD, et al. Relationship between male pattern baldness and the risk of aggressive prostate cancer: An analysis of the Prostate, Lung, Colorectal, and Ovarian Cancer Screening Trial. J Clin Oncol 2014;Sep 15. pii: JC0.2014.55.4279

24. De Marzo AM, Platz EA, Sutcliffe S, et al. Inflammation in prostate carcinogenesis. Nat Rev Cancer 2007;7:25669. http://dx.doi.org/10.1038/nrc2090

25. Zlotta AR, et al. Unpublished data presented at the 2014 University of Toronto Urology Update, November $1,2014$.

26. Burnett AL. Erectile dysfunction following radical prostatectomy. JAMA 2005;293:2648-53. http://dx.doi. org/10.1001/jama.293.21.2648 
27. Montorsi F, Guazzoni G, Strambi LF, et al. Recovery of spontaneous erectile function after nerve-sparing radical retropubic prostatectomy with and without early intracavernous injections of alprostadil: Results of a prospective, randomized trial. J Urol 1997;158:1408-10. http://dx.doi.org/10.1016/S0022$5347(01) 64227-7$

28. Padma-Nathan H, McCullough AR, Levine LA, et al. Randomized, double-blind, placebo-controlled study of postoperative nightly sildenafil citrate for the prevention of erectile dysfunction after bilateral nerve-sparing radical prostatectomy. Int J Impot Res 2008;20:479-86. hittp://dx.doi.org/10.1038/iiir.2008.33

29. Montorsi $F$, Brock $G$, Lee J, et al. Effect of nightly versus on-demand vardenafil on recovery of erectile function in men following bilateral nerve-sparing radical prostatectomy. Eur Urol 2008;54:924-31. http://dx.doi. org/10.1016/i.eururo.2008.06.083

30. Montorsi F, Brock G, Stolzenburg JU, et al. Effects of tadalafil treatment on erectile function recovery following bilateral nerve-sparing radical prostatectomy: A randomised placebo-controlled study (REACTT). Eur Urol 2014;65:587-96. http://dx.doi.org/10.1016/j.eururo.2013.09.051

31. Pavlovich CP, Levinson AW, Su LM, et al. Nightly vs on-demand sildenafil for penile rehabilitation after minimally invasive nerve-sparing radical prostatectomy: Results of a randomized double-blind trial with placebo. BJU Int 2013;112:844-51. http://dx.doi.org/10.1111/bju.12253

32. Dalkin BL, Christopher BA. Preservation of penile length after radical prostatectomy: Early intervention with a vacuum erection device. Int J Impot Res 2007;19:501-4. http://dx.doi.org/10.1038/si.jiir.3901561

33. Köhler TS, Pedro R, Hendlin K, et al. A pilot study on the early use of the vacuum erection device after radical retropubic prostatectomy. BJU Int 2007;100:858-62. http://dx.doi.org/10.1111/j.1464-410X.2007.07161.

34. Raina R, Pahlajani $G$, Agarwal A, et al. The early use of transurethral alprostadil after radical prostatectomy potentially facilitates an earlier return of erectile function and successful sexual activity. BJU Int 2007;100:131721. hitp://dx.doi.org/10.1111/j.1464-410X.2007.07124.x

35. Titta M, Tavolini IM, Dal Moro F, et al. Sexual counseling improved erectile rehabilitation after non-nervesparing radical retropubic prostatectomy or cystectomy — results of a randomized prospective study. I Sex Med 2006;3:267-73. http://dx.doi.org/10.1111/j.1743-6109.2006.00219.x

36. Gormley EA, Lightner DJ, Burgio KL, et al. Diagnosis and treatment of overactive bladder (non-neurogenic) in adults: AUA/SUFU guideline. J Urol 2012;188(6Suppl):2455-63. http://dx.doi.org/10.1016/i. juro.2012.09.079

37. van Kerrebroeck P, Chapple C, Drogendijk T, et al. Combination therapy with solifenacin and tamsulosin oral controlled absorption system in a single tablet for lower urinary tract symptoms in men: Efficacy and safety results from the randomised controlled NEPTUNE trial. Eur Urol 2013;64:1003-12. http://dx.doi.org/10.1016/i. eururo.2013.07.034

38. Maman K, Aballea S, Nazir J, et al. Comparative efficacy and safety of medical treatments for the management of overactive bladder: A systematic literature review and mixed treatment comparison. Eur Urol 2014;65:755-65. http://dx.doi.org/10.1016/i.eururo.2013.11.010

39. Abrams P, Kelleher C, Staskin D, et al. Combination treatment with mirabegron and solifenacin in patients with overactive bladder: Efficacy and safety results from a randomised, double-blind, dose-ranging, phase 2 study (Symphony). Eur Urol 2014; Epub 2014 Feb 19. http://dx.doi.org/10.1016/i.eururo.2014.02.012

40. Nitti VW, Dmochowski R, Herschorn S, et al. OnabotulinumtoxinA for the treatment of patients with overactive bladder and urinary incontinence: Results of a phase 3, randomized, placebo controlled trial. J Urol 2013;189:2186-93. htrp://dx.doi.org/10.1016/i.juro.2012.12.022

41. Dowson C, Khan MS, Dasgupta P, et al. Repeat botulinum toxin-A injections for treatment of adult detrusor overactivity. Nat Rev Urol 2010;7:661-7. http://dx.doi.org/10.1038/nrurol.2010.187

42. Mohee $\mathrm{A}$, Khan $\mathrm{A}$, Harris $\mathrm{N}$, et al. Long-term outcome of the use of intravesical botulinum toxin for the treatment of overactive bladder (OAB). BJU Int 2013;111:106-13. http://dx.doi.org/10.1111/i.1464410X.2012.11282.x

43. Cornu JN, Abrams P, Chapple CR, et al. A contemporary assessment of nocturia: Definition, epidemiology, pathophysiology, and management-a systematic review and meta-analysis. Eur Urol 2012;62:877-90. http://dx.doi.org/10.1016/j.eururo.2012.07.004
44. Weiss JP, Zinner NR, Klein BM, et al. Desmopressin orally disintegrating tablet effectively reduces nocturia: Results of a randomized, double-blind, placebo-controlled trial. Neurourol Urodyn 2012;31:441-7. http:// dx.doi.org/10.1002/nau.22243

45. Juul KV, Klein BM, Nergaard JP. Long-term durability of the response to desmopressin in female and male nocturia patients. Neurourol Urodyn 2013;32:363-70. htrp://dx.doi.org/10.1002/nau.22306

46. Sand PK, Dmochowski RR, Reddy J, et al. Efficacy and safety of low dose desmopressin orally disintegrating tablet in women with nocturia: Results of a multicenter, randomized, double-blind, placebo controlled, parallel group study. J Urol 2013;190:958-64. http://dx.doi.org/10.1016/i.juro.2013.02.037

47. Wang $\mathrm{CJ}$, Lin YN, Huang SW, et al. Low dose oral desmopressin for nocturnal polyuria in patients with benign prostatic hyperplasia: A double-blind, placebo controlled, randomized study. J Urol 201 1;185:219-23. http:// dx.doi.org/10.1016/i.juro.2010.08.095

48. Berges R, Höfner $K$, Gedamke $M$, et al. Impact of desmopressin on nocturia due to nocturnal polyuria in men with lower urinary tract symptoms suggestive of benign prostatic hyperplasia (LUTS/BPH). World I Urol 2014;32:1163-70. http://dx.doi.org/10.1007/s00345-014-1381-7

49. Peters $K M$, Carrico DJ, Wooldridge $L S$, et al. Percutaneous tibial nerve stimulation for the long-term treatment of overactive bladder: 3-year results of the STEP study. J Urol 2013;189:2194-201. http://dx.doi. org/10.1016/i.juro.2012.11.175

50. Clemens JQ, Anger JT, Ganz ML, et al. Costeffectiveness of sacral neuromodulation and botulinum toxin-A for patients with refractory idiopathic overactive bladder [abstract]. Neurourol Urodyn 2012;2:223.

51. Maheshwari PN, Andankar MG, Bansal M. Nephrostomy tube after percutaneous nephrolithotomy: Large-bore or pigtail catheter? J Endourol 2000;14:735-7. http://dx.doi.org/10.1089/end.2000.14.735

52. De Sio M, Autorino R, Quattrone C, et al. Choosing the nephrostomy size after percutaneous nephrolithotomy. World J Urol 2011;29:707-11. http://dx.doi.org/10.1007/s00345-010-0587-6

53. Liatsikos $\mathrm{EN}$, Hom D, Dinlenc $\mathrm{CZ}$, et al. Tail stent versus re-entry tube: A randomized comparison after percutaneous stone extraction. Urology 2002;59:15-9. http://dx.doi.org/10.1016/S0090-4295(01)01475-3

54. Pietrow PK, Auge BK, Lallas CD, et al. Pain after percutaneous nephrolithotomy: Impact of nephrostomy tube size. J Endourol 2003;17:411-4. http://dx.doi.org/10.1089/089277903767923218

55. Desai MR, Kukreja RA, Desai MM, et al. A prospective randomized comparison of type of nephrostomy drainage following percutaneous nephrostolithotomy: Large bore versus small bore versus tubeless. I Urol 2004; 172:5657. http://dx.doi.org/10.1097/01.ju.0000130752.97414.c8

56. Marcovich R, Jacobson Al, Singh J, et al. No panacea for drainage after percutaneous nephrolithotomy. J Endourol 2004;18:743-7. http://dx.doi.org/10.1089/end.2004.18.743

57. Shen $P$, Liu $Y$, Wang J. Nephrostomy tube-free versus nephrostomy tube for renal drainage after percutaneous nephrolithotomy: A systematic review and meta-analysis. Urol Int 2012;88:298-306. http://dx.doi. org $/ 10.1159 / 000332151$

58. Szymanski KM, Misseri R, Whittam B, et al. Mortality after bladder augmentation in children with spina bifida. J Urol 2014 Epub Jul 27. htrp://dx.doi.org/10.1016/i.juro.2014.07.101

59. Metcalfe PD, Cain MP, Kaefer M, et al. What is the need for additional bladder surgery after bladder augmentation in childhood? J Urol 2006;176(4 Pt 2):1801-5.

60. Rosenbaum DH, Cain MP, Kaefer M, et al. Ileal enterocystoplasty and B12 deficiency in pediatric patients. J Urol 2008;179:1544-7. http://dx.doi.org/10.1016/i.juro.2007.11.089

61. Husmann D. Cost-effectiveness of cystoscopy and urine cytology in augmented bladders. American Urological Association. Chicago, IL, 2009.

62. Soergel TM, Cain MP, Misseri R, et al. Transitional cell carcinoma of the bladder following augmentation cystoplasty for the neuropathic bladder. J Urol 2004;172(4 Pt 2):1649-51.

63. Higuchi TT, Granberg CF, Fox JA, et al. Augmentation cystoplasty and risk of neoplasia: Fact, fiction and controversy. J Urol 2010;184:2492-6. hittp://dx.doi.org/10.1016/i.juro.2010.08.038

64. Szymanski KM, Misseri R, Whittam B, et al. Cutting for stone in augmented bladders-what is the risk of recurrence and is it impacted by treatment modality? J Urol 2014;191:1375-80. 
Funding in the form of an educational grant

was provided by

Astellas Pharma Canada, Inc.

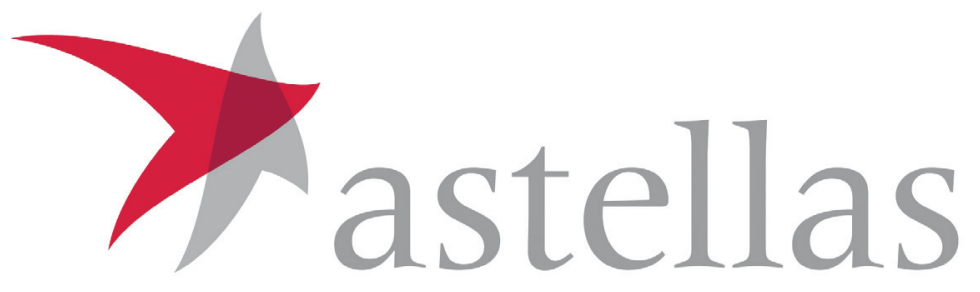

and

Bayer Canada, Inc.

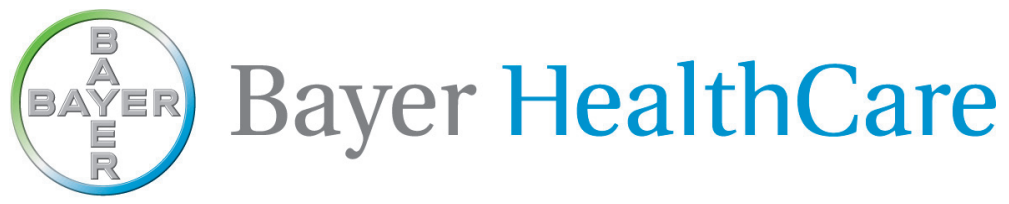

